\title{
Uma reflexão sobre a relação humano-animal na sociedade contemporânea e a ligação com a geografia
}

\author{
Una reflexión sobre la relación humano-animal en la sociedad \\ contemporánea y conexión con la geografía
}

\section{A reflection on human-animal relationship in contemporary society and its connection with geography}

\author{
Fábio Luiz Zanardi Coltro \\ fcoltro@sercomtel.com.br \\ Universidade Estadual de Londrina
}

\begin{abstract}
Resumo: O surgimento de um novo campo de investigação, a geografia cultural animal (animal geographies), vem despertando o interesse da academia. Nessa trilha, diversos trabalhos, investigações e pesquisas se pautam basicamente sobre dois grandes eixos de discussão: o que concerne ao animal propriamente dito e o que se volta para as complexas e controversas relações humano-animal. Filófosos vêm, ao longo dos anos, discutindo essa última vertente dos estudos animais; no entanto, pouco se abordou sobre a hierarquização moral nessa complexa relação. O presente artigo tem como objetivo a discussão dessa hierarquização moral nas relações humano-animal e seus desdobramentos no campo social e moral que se encaminha no pensamento da Geografia contemporânea. Nesse escopo pretende-se estudar, a partir da perpectiva da non-representational theory, as relações humano-animal em diferentes culturas e estratos sociais com relação a seu valor sociológico, geográfico e ético. Seria esse o início de uma geografia humano-animal?
\end{abstract}

Palavras-chave: Geografia. Animais. Sociedade contemporânea. Ética.

Resumen: La aparición de un nuevo campo de investigación, mascota geografía cultural (geografías animales), han atraído el interés de la academia. En esta pista, varios estudios, investigaciones y estudios analizan básicamente en dos áreas principales de discusión: lo que se refiere al animal adecuadamente y tuvo que volver a las relaciones entre humanos y animales complejos y controvertidos. Filófosos vienen, en los últimos años, hablando de la última parte de los estudios con animales, sin embargo, poco se discute acerca de la jerarquía moral de esta compleja relación. Este artículo tiene como objetivo discutir esta jerarquía moral en las relaciones entre humanos y animales y sus consecuencias sobre los delanteros sociales y morales en el pensamiento de la geografía contemporánea. Este ámbito tiene por objeto estudiar, partindo de la teoría no-representacional, las relaciones entre humanos y animales en diferentes culturas y clases sociales en relación con su valor sociológico, geográficos y éticos. Este sería el comienzo de una geografía humana-animal?

Palabras clave: Geogafia. Los animales. La sociedad contemporânea. La ética. 


\begin{abstract}
The emergence of a new field of research, the animal cultural geography (Animal geographies), is beginning to attract the interest of the academy. In this track, several studies, investigations and researches discuss basically two main areas: what concerns the animal itself and what turns to the complex and controversial humananimal relationships. Philosophers had been discussing, over the years, the latter part of the animal studies; however, little was discussed about the moral hierarchy in this complex relationship. This article aims to discuss this moral hierarchy in the humananimal relations and its social and moral consequences for contemporary Geography. Within this scope we intend to study, from the perspective of the non-representational theory, human-animal relations in different cultures and social strata in relation to its sociological, geographical and ethical values. Would this be the beginning of a humananimal Geography?
\end{abstract}

Keywords: Geography. Animals. Contemporary society. Ethics.

\title{
INTRODUÇÃO
}

O interesse sobre o relacionamento humano-animal tem se expandido consideravelmente nos últimos anos, intelectual, política e legalmente. Esse interesse, segundo Maria Esther Maciel (2011), possibilitou o surgimento de um novo campo da investigação que, sob a denominação de Estudos Animais, vem se afirmando como um espaço de entrecruzamento de várias disciplinas oriundas das ciências humanas e biológicas, principalmente em torno de dois grandes eixos de discussão: o que concerne ao animal propriamente dito e à chamada animalidade, as complexas e controversas relações humano-animal. Portanto, torna-se evidente a emergência do tema como um fenômeno transversal, que corta obliquamente diferentes campos do conhecimento e propicia novas maneiras de reconfigurar, fora dos domínios do antropocentrismo e do especismo, o próprio conceito de humano.

Ademais discussões e publicações na década de 1990 têm chamado a atenção da Geografia para a temática (WOLCH; EMEL, 1995; PHILO; WILBERT, 2000).

A Zoologia despertou o interesse na relação humano-animal (FRANKLIN, 1999), junto com outras ciências como a Geografia, a Sociobiologia, a Psicologia, a Veterinária, entre outras (FRANKLIN, 1999). As disciplinas com maior familiaridade com a temática dos Estudos Animais (MACIEL, 2011) têm sido a Antropologia Social, a História e a Filosofia, mas poucos são os pontos em comum nessa discussão. Além disso, Wolch e Emel (1995) trazem novamente a questão animal ao âmbito da Geografia. De fato, afirma Franklin (1999), do ponto de vista da Sociologia essa separação dos projetos acadêmicos estáo entre os muitos tipos de comportamento e pressupostos na modernidade que exigem explicação.

As relações humano-animal têm se tornado foco de diversas discussões na ciência contemporânea. Uma breve verificação na literatura mostra o avanço das pesquisas na referida temática. Esse avanço inclui: a questão da filosofia e política dos direitos dos animais (BENTON, 1993; MIDGELY, 1983; SINGER, 2004; ROLLIN, 2006; REGAN, 2006); 
a sociologia dos direitos dos animais (TESTER, 1992); a história da relação humanoanimal (RITVO, 1987; THOMAS, 1983); a antropologia social das relações humano-animal (CARTMILL, 1993; INGOLD, 1994); animais como comida e nas dietas (BOUDIEU, 2011; DOUGLAS, 1975; FIDDES, 1991; GOODMAN; REDCLIFT, 1991; MENNELL, 1993; TWIGG, 1983; VIALLES, 1994); animais de companhia ou PET (SERPELL, 1995, 1996; SERPELL; PAUL, 2006). A relação humano-animal é, também, uma importante dimensão nos recentes artigos na agenda da Sociologia da natureza (MACNAGHTEN; URRY, 1995; MURPHY, 1995)

As possibilidades de uma geografia da relação humano-não-humano são, portanto, muito maiores do que a estimulada pela História ou Filosofia. Alguns desses escopos estão estabelecidos pela natureza cada vez mais controversa e conflituosa das relações homem-animal em número maior de campos no século XX: pecuária e indústria de alimentos; adoção e convivência com pets; animais e esporte; alterações no paladar em relação aos animais e peixes como alimento; o domínio do espaço urbano, etc. (PHILO; WILBERT, 2000).

Assim, questiona-se porque devemos restringir nossa teoria e prática moral apenas aos humanos? O que faz algo ser objeto de nossa preocupação moral, digno de nossa atenção moral? O que trás algo para nossa arena moral? O que torna algo objeto de nossa ética?

Os animais devem estar no âmbito de nossas preocupações morais, tanto quanto os humanos, por isso devemos rever nossa história, assim como os aspectos diários de nossa vida cotidiana, sob uma nova perspectiva.

Segundo Rollin:

[...] quando se trata, no entanto, do status moral dos animais, as nossas intuições são misturadas, incipientes e inconsistentes: por exemplo, podemos sentir que o nosso cão é um objeto de nossa preocupação moral, mas não os dos nossos vizinhos, e eles, por sua vez, podem sentir exatamente o oposto. (ROLLIN, 2006 p. 35)

Ou, segue o filófoso, "podemos acreditar ser plausível matar dez tigres siberianos, desde que eles não sejam os últimos dez tigres siberianos". (ROLLIN, 2006 p. 35)

Ao lidar com a questão do status moral dos animais, nossas intuições, tanto individuais como sociais, enviam mensagens contraditórias. É evidente que tanto a teoria tradicional moral e a prática moral tradicional têm falhado para lidar adequadamente com o status moral do animal. Como Kant observou, a teoria ética não pode soar livre, sem restrições, mas deve ser amarrada ao senso comum, prática comum, e experiência moral comum. A obrigação moral do homem para com os animais não pode ressoar somente nos corações, mas nas mentes e, finalmente, nas práticas das pessoas na sociedade, caso contrário obrigação moral não terá nenhum valor.

De fato, há uma significativa mudança nos hábitos e consumos com relação aos animais, mas podemos verificar essas mudanças como a formação de um ideal de tratamento dos animais, ou melhor, podemos ver tais mudanças como uma inclusão gradativa dos animais no nosso círculo moral? Como a hierarquização/priorização dos animais 
afeta nossa consideração moral? Quais as diferenças entre as ações morais em relação aos animais em culturas diferentes?

As poucas discussões feitas, como a de Lawrence C. Becker (1989), propondo a questão da hierarquização como efeito do distanciamento social, têm sido muito criticadas e consideradas argumentativamente fracas. Esse é o ponto central de nossa discussão. Como agimos e como "devemos" agir com relação aos animais? Como se processa essa hierarquização/priorização dos animais?

O presente artigo buscará avaliar os discursos e práticas de proprietários de animais, criadores, tratadores e consumidores, na busca dos elementos centrais que balizem essa hierarquização e suas consequências na dinâmica socioespacial.

Trazendo a questão animal para a discussão geografia, faz-se necessária à retomada de toda a discussão sobre a questão animal e suas diversas vertentes.

\section{A RELAÇÃO HUMANO-ANIMAL}

Historicamente a relação da Geografia com os não humanos tem sido motivo de tensão e conflitos. Enquanto os antropólogos físicos têm estudado há muitas décadas o comportamento dos primatas não humanos com a finalidade de melhor entender e explicar características comuns entre os humanos e os seus parentes mais próximos, os sociólogos têm-se recusado a olhar para as culturas, estruturas e organizações sociais dos outros animais para produzir inferências que contribuam para melhor entender alguns dos comportamentos sociais humanos (ver, por exemplo, GIDDENS, 2005 ou GIDDENS, 2003). Para muitos antropólogos e sociólogos, os "animais" (não humanos) continuam a constituir-se como os últimos "outros". Portanto não será surpreendente ver que a Antropologia e a Sociologia evoluíram, enquanto ciências, em contextos marcadamente pautados pelo paradigma antropocêntrico (ARLUKE; SANDERS, 1996; FRANKLIN, 1999; NIBERT, 2002; COSTA, 2004; CASANOVA, 2006).

Assim, a forma como organizamos as percepções e como categorizamos a realidade relativa aos "outros" (YZERBYT; LEYENS, 2004; BARON et al., 2007; SMITH; MACKIE 2007) - sejam eles humanos ou não humanos - acaba por receber influências profundas desse paradigma e de noutros em que se baseiam as culturas ocidentais da contemporaneidade (GIDDENS, 2005; GIDDENS, 2003; ALCOCK et al., 2005; ARONSON et al., 2007

Dimensões como a religiosa, ideológica, política e filosófica estão embebidas no background individual de cada "eu", contribuindo para a formação de percepções que se manifestam em determinados comportamentos e atitudes sobre o "outro" (MCGARTY, 1999; CIALDINI 2001; AIKEN, 2002; COSTA, 2004; ALBARRACIN et al., 2005; CASANOVA, 2006). Adicionalmente o "eu" forma preconceitos sobre o "outro" (MACRAE et al., 1996; JONES 2002; NELSON, 2006), sendo que o oposto também se observa: essa alteridade faz parte do processo de comparação social (YZERBYT e LEYENS, 2004; BARON et al., 2007; SMITH; MACKIE 2007). Dessa forma, o preconceito especissista do antropocentrismo é operante na Sociologia e na Antropologia. 
Já no campo da ética, nossas intuições espontâneas nos sugerem que é moralmente condenável atormentar os animais. Desde o século XIX, muitas legislações registraram essas exigências humanitárias e proibiram os maus-tratos infligidos aos animais domésticos. Formas inéditas de apropriação do animal vivo (criação intensiva, experimentação, transgenose), porém, conduziram a um aumento da instrumentalização: sob a pressão de interesses econômicos diversos e na "ausência" da intenção de fazer mal, os seres humanos infligem certamente a um imenso número de animais tratamentos mortíferos ou que vão em sentido contrário a seu bem-estar (CARRUTHERS 1992).

Ao mesmo tempo, a difusão de temas inspirados na etologia, na sociobiologia e na teoria da evolução transformou profundamente a percepção comum do mundo animal; a animalidade não mais é vista necessariamente como o inverso inquietante da humanidade. A isso se juntam as ameaças que pesam sobre as espécies selvagens em função do desenvolvimento das sociedades industriais: alguns chegam a considerar que existe uma verdadeira solidariedade entre as formas de vida humana e animais. (CHAPOUTHEIR; NOUET, 1997)

Consequentemente, o tratamento do animal tornou-se um problema social (com seus militantes, sua imprensa, seus grupos de pressão, seus integristas, etc.); é igualmente uma questão central em ética aplicada. O mínimo que se pode dizer é que as concepções tradicionais do tratamento ético animal foram radicalmente questionadas. (DIERAUER, 1977)

\section{CONCEPÇÕES TRADICIONAIS}

A concepção tradicional constitui-se desde a Antiguidade, e é possível que ela seja o eco de temas aristotélicos e estoicos (PASSMORE, 1980, p. 120). A idéia essencial é aquela que pertence à comunidade moral e coincide com a posse e o exercício da razão.

Em São Tomás de Aquino, o animal desprovido de inteligência e de vontade, isto é, de apetite racional, é incapaz de intenção moral; ele é igualmente incapaz de eleição de meios (escolha, consentimento e uso não convêm à sua natureza); enfim, seus atos não são, propriamente falando, imperados, isto é, comandados pela vontade (LINZEY, 1987). Em Kant, o animal não pode agir à base de princípios, pois é incapaz de formar o conceito de lei universal e necessária (LINZEY, 1987). Ele tampouco tem a capacidade de determinar racionalmente seus próprios fins, capacidade que confere à humanidade o estatuto de fim em si. Portanto, ele está em princípio excluído da comunidade moral ideal, a saber, o reino dos fins (LEAHY, 1991).

Isso, porém, não que dizer que o animal não conte em absoluto. Tomás de Aquino provavelmente admitiria a fórmula aristotélica: “Não há nada que choque a razão se alguns traços psíquicos são os mesmos no homem e nos outros animais, se outros apresentam fortes semelhanças e se outros ainda têm relações de analogia" (LINZEY, 1987).

Além disso, toda criatura tende a realizar sua própria perfeição, feita de similitude com a bondade e a perfeição divinas e de participação nessas. As mais humildes criaturas 
executam, a seu modo, a vontade divina e manifestam dessa forma uma perfeição que lhes é apropriada: portanto, elas não são em nada desprezíveis. Enfim, é a marca de uma índole misericordiosa sentir piedade dos sofrimentos suportados pelos animais. A situação é um pouco comparável em Kant; os animais, como criaturas vivificadas por uma alma, são análogos ao homem, que, em acréscimo, é habitado por um espírito (GOFFI, 1994).

\section{Para Feinberg:}

Há, portanto, obrigações de que os animais são os beneficiários, na medida em que a humanidade seja promovida pelo cumprimento dessas obrigações. Assim, é lícito matá-los em caso de necessidade, mas não fazê-los sofrer; impor-lhes um trabalho, contanto que este não exceda suas forças, etc. É a teoria das obrigações indiretas (FEINBERG, 1974, p. 43-68).

Para cada uma dessas tradições podemos localizar dissidências. Pelizzoli invoca uma inspiração kantiana, mas considera que o princípio da moral consiste em impor limites à própria vontade, levando em conta os interesses daqueles que vão ser afetados pelas ações do agente (PELIZZOLI, 2003).

A personalidade depende assim da existência de interesse, e não é absurdo falar de direitos dos animais. Alguns teólogos ou filósofos de inspiração religiosa contestam, no momento atual, o antropocentrismo ético do cristianismo (CLARK, 1977). Assim, Linzey elaborou uma teoria dos Theos-Rights (direitos fundados na divindade), de que os animais gozariam. A ideia essencial é que as criaturas animais possuem um valor inerente aos olhos de seu Criador. Fazer-lhes um mal é fazer um mal a Deus em sua criação (LINZEY, 1987).

\section{A AFIRMAÇÃO DOS DIREITOS DO ANIMAL}

As concepções tradicionais se recusam a admitir a existência de direitos cujos titulares seriam os animais. Nós (os seres humanos) não compomos uma sociedade de direito com os animais (AGOSTINHO apud LINZEY, 1987). Vários autores contemporâneos contestam essa idéia e afirmam a existência de direitos dos animais; eles pensam antes de tudo em direitos-títulos (ou em direitos-requerimentos), isto é, em direitos definíveis em termos de obrigações correlativas (REGAN, 2006).

Refletindo sobre o estatuto das legislações protetoras dos animais, Feinberg conclui que elas são promulgadas a fim de que os animais sejam os beneficiários diretos de uma proteção legal, mas, como são incapazes de demandar em justiça, eles devem necessariamente ser representados numa ação jurídica (FEINBERG, 1974).

Coloca-se então a questão de saber quem é suscetível de ser representante nesse caso. Segundo Feinberg:

Trata-se aqui de interesses por oposição a uma vontade. Basta ser o possuidor de interesses para ser o beneficiário de alguma coisa: quem tem interesses tem, pela mesma 
razão, um bem próprio. Os interesses, por sua vez, dependem da existência de uma "vida conativa" (FEINBERG, 1974, p. 43).

Trata-se de uma vida em que se manifestam desejos, os quais pressupõem crenças. A seu ver, os interesses dos animais são essencialmente interesses de bem-estar; eles não são construtivos de direitos fortes (como o direito à vida) (FEINBERG, 1974). Cumpre observar, enfim, que ele pensa, antes de tudo, em direitos jurídicos; no entanto, parece admitir que essas análises podem ser transpostas para o domínio dos direitos morais, que constituem os princípios de uma consciência esclarecida. Bernard Rollin (2006) considera que os direitos jurídicos têm por função proteger os interesses constitutivos do indivíduo contra os caprichos e a arbitrariedade dos outros.

Nesse sentido, os direitos jurídicos têm uma dimensão moral: conceder direitos jurídicos ao indivíduo é reconhecer-lhe um valor intrínseco. A presença de um telos indica que lidamos com um indivíduo que possui tal valor. Rollin define telos como uma natureza, uma função, uma série de atividades intrínsecas a um ser vivo; essa natureza é determinada pela evolução, faz parte do equipamento genético do ser vivo e o constitui como tal. Uma concepção tão nitidamente teológica da natureza animal o leva a criticar duramente o reducionismo científico, especialmente em sua versão behaviorista (ROLLIN, 2006).

Tom Regan é o mais conhecido e o mais sistemático defensor dos direitos animais. Seu método é intuicionista. A reflexão ética não se lança no vazio: trata-se de escolher entre diferentes teorias morais concorrentes (versões do consequêncialismo; diversas teorias deontológicas; contratualismo) (REGAN, 2006). Inspirando-se no procedimento rawlsiano do equilíbrio reflexo, Regan faz um exame de nossas intuições espontâneas, purgando-as de sua inconsistência, de sua imprecisão, daquilo que as complica inutilmente, do que elas podem comportar de ideias preconcebidas: aparecem então intuições ou crenças refletidas (REGAN, 2006).

A teoria ética que melhor sistematizar essas intuições refletidas será retida. Somente uma teoria ética fundada sobre os direitos é capaz de justificar adequadamente a intuição refletida, segundo a qual não é permitido tratar de qualquer maneira os animais, isto é, segundo a qual restrições normativas pesam sobre a conduta dos seres humanos em relação a "mamíferos normais, com idade de um ano ou mais" (REGAN, 2006, p. 408).

Para Tom Regan:

Todos pensam que é, no mínimo, moralmente condenável causar danos injustificados aos animais, mas uma teoria das obrigações indiretas naquilo que lhes concerne não é capaz de justificar tal princípio: com efeito, tal teoria identifica a comunidade moral com a comunidade dos agentes morais (o agente moral é capaz de agir seguindo princípios; ele é dotado de livre-arbítrio e pode, portanto, deliberar) (REGAN, 2006, p. 410).

Em relação aos pacientes morais, os membros da comunidade moral têm apenas obrigações indiretas, mas uma teoria das obrigações indiretas (egoísmo ético, kantismo, contratualismo) é incapaz de explicar por que o princípio segundo o qual não se deve 
causar danos aos indivíduos aplica-se diretamente aos agentes morais, e a eles somente: os pacientes morais também podem ter a experiência de um bem-estar suscetível de ser afetado negativamente (REGAN, 2006).

Eles podem assim sofrer um dano direto, contrariamente à afirmação central da teoria tradicional. Entretanto, nem toda teoria das obrigações direta é admissível. Por exemplo, uma concepção que condena a crueldade para com os animais e recomenda a bondade em relação a eles negligencia um fato evidente: pode-se causar um dano a alguém sem ter uma intenção cruel (PASSMORE, 1980).

Sob outro ponto de vista, um utilitarismo do ato (utilitarismo hedonista ou utilitarismo da preferência) apresenta consequências contrárias à intuição: pode-se, para maximizar a utilidade, infligir de forma muito não igualitária sérios danos aos agentes morais (SINGER, 2004). Em outras palavras, o princípio segundo o qual não se deve infligir danos aos indivíduos depende de um princípio de ordem mais elevada, o princípio de justiça, segundo o qual se deve atribuir a cada um o que lhe cabe (SORABJI, 1995).

O utilitarismo da regra não consegue explicar por que, em boa justiça, pode haver obrigações diretas para com os pacientes morais (incapazes de reivindicar um tratamento equitativo); e as éticas perfeccionistas justificam tratamentos não apenas diferenciais, mas também discriminatórios (SAPONTZIS, 1987). A fraqueza maior de tais análises decorre de que nelas os indivíduos só contam na medida em que realizam um valor "localizado noutra parte que não neles mesmos [utilidade, excelência do agir]" (MIDGLEY, 1983).

Regan pensa então que o princípio de justiça só é inteligível se os indivíduos têm um valor neles mesmos. Esse valor não é nem um estado mental, tampouco uma virtude. Trata-se do valor inerente, diferente do valor intrínseco, que depende sempre de experiência mentais vividas pelo próprio indivíduo, por um outro indivíduo ou por outros indivíduos (REGAN, 2006).

Resta saber o que confere aos indivíduos um valor inerente. Ser o sujeito de uma vida é suficiente para fazer do indivíduo o titular de um valor inerente. Alguém é o sujeito de uma vida se experimenta desejos e preferências; se é capaz de ter percepções e lembranças; se pode agir intencionalmente em função de um objetivo; se é dotado de sensibilidade e se tem uma vida emocional; se tem um senso do futuro, inclusive de seu próprio futuro; se manifesta uma identidade psicológica através do tempo; mas, de forma mais decisiva ainda, se tem bem-estar individual do qual possa ter a experiência própria através do tempo (SINGER, 2004).

Regan considera certamente que o bem-estar (welfare) é a ocasião de uma experiência própria de um tipo muito particular, caso contrário se compreenderia mal a distinção entre o valor inerente (que pertence à entidade ela mesma) e o valor intrínseco (que depende de uma experiência) (REGAN, 2006). Seja como for, o primeiro dos direitos, que pertence igualmente aos agentes morais e aos pacientes morais, é o direito de ser tratado com respeito. Esse direito torna a forma de um título contra os agentes morais: não se pode jamais causar um dano ao indivíduo que tenha um valor inerente, sob pretexto de que esse dano poderia promover o que tem somente um valor intrínseco (prazer, satisfação de preferências) em relação ao que não o tem (desprazer, frustração de preferências) (MAGEL, 1989). 
Contudo, Regan não pensa que o direito de ser tratado com respeito seja absoluto. Nossas crenças refletidas nos indicam, com efeito, que às vezes é lícito ir além do direito de não sofrer danos. Ele desenvolve então uma teoria destinada a precisar em que circunstâncias e em que condições é aceitável causar um dano ao inocente ou à menoridade (REGAN, 2006).

A ideia essencial é que não poderíamos nos contentar em minimizar a quantidade total de danos infligidos a todos os que serão afetados pelas consequências da ação, incluídos os efeitos secundários (REGAN, 2006). Em decorrência dessa análise, a maneira como os seres humanos tratam os pacientes morais, que são os animais, é, na maior parte do tempo, radicalmente imoral. Eles não lhes infligem danos (causar a morte, sofrimentos) por razões moralmente justificáveis nem respeitam princípios mínimos de justiça distributiva (REGAN, 2006). Regan (1983) condena, portanto, absolutamente a caça, a criação industrial de animais, a alimentação à base de carne e a experimentação animal.

\section{A LIBERAÇÃO ANIMAL}

Peter Singer, principal teórico da liberação animal, pensa que é possível dispensar a noção dos direitos. Segundo ele, é mais exato teoricamente e mais eficaz praticamente considerar os animais uma menoridade e emancipá-los. Nisso ele é herdeiro de Jeremy Bentham, que opõe a melhoria da condição dos escravos pelo Código Negro, de Luís XIV, e ao tratamento ainda tirânico dos animais (SINGER, 2004).

A propósito destes últimos, J. Bentham, afirma: “A questão não é, Eles podem raciocinar?, nem Eles podem falar?, mas Eles podem sofrer?" (BENTHAM apud SINGER, 2004 p. 283). O utilitarismo de P. Singer deve igualmente muito ao prescritivismo universal de R. M. Hare, de quem foi discípulo (HARE, 1993).

R. M. Hare pensa que:

[...] a exigência de universalidade, constitutiva da postura moral, toma concretamente a seguinte forma: colocar-nos, em imaginação, no lugar daqueles que serão afetados pelas consequências de nossa ação e perguntar-nos até que ponto aceitaríamos ver seus interesses afetados como os nossos o seriam (HARE, 1993, p. 326).

Peter Singer radicaliza essa conclusão ao admitir que não são apenas os interesses humanos que devemos levar em conta nessa questão, mas os de toda criatura dotada de sensibilidade. A tese central da liberação animal é, portanto, a afirmação da igual consideração dos interesses de todos aqueles, inclusive os animais, que terão de sofrer as consequências de uma ação (SINGER, 1989).

Singer julga que:

É especista não levar em conta igualmente os interesses de todos os seres sensíveis (isto é, capazes de experimentar prazer e dor), concernidos pela consequência de uma ação. O especismo é uma forma de discriminação análoga ao racismo e ao sexismo: ele consiste em não levar em conta igualmente os interesses dos membros de uma outra 
espécie pelo simples motivo de pertencerem a uma outra espécie, mas a liberação animal não implica o tratamento indiferenciado de todos os seres sensíveis (SINGER, 2004 p. 275).

A igualdade na consideração dos interesses não significa igualdade no tratamento. O que pode fundamentar um tratamento diferencial? Para responder a essa questão, Singer formula uma teoria do valor da vida em termos utilitaristas, mitigados por elementos que provêm da ética da pessoa: devemos distinguir entre os seres conscientes de si mesmos e os que são simplesmente conscientes (SINGER, 2004).

No que concerne a estes últimos, uma concepção total do utilitarismo prevalece o argumento da maior felicidade, onde somos autorizados a só levar em conta a quantidade total de felicidade, a destruição de um ser consciente podendo ser compensada pela criação de um outro ser consciente, suscetível de experimentar ao menos a mesma felicidade que o primeiro teria experimentado se continuasse a viver (SINGER, 1989).

No que concerne aos primeiros, aplica-se uma concepção do utilitarismo limitada à existência prévia: na medida em que se trata de entidades distintas, dotadas de um passado e de um futuro próprios, uma simples comparação entre quantidades impessoais de felicidade não basta (SINGER, 2004).

$\mathrm{O}$ argumento da substituição não funciona, e esses sujeitos de uma vida devem se beneficiar de uma proteção mais obrigatória. Peter Singer foi levado a modificar de forma significativa essa análise e a abandonar a dupla norma: concepção total do utilitarismo para os seres conscientes, concepção limitada à existência prévia para os seres conscientes de si mesmos (SINGER, 2004).

Mas as retificações não modificam substancialmente as implicações práticas da liberação animal: condenação da criação industrial de animais e da maior parte das formas de experimentação animal, caráter moralmente obrigatório de uma alimentação vegetariana, etc. (SINGER, 2004).

\section{CONTRA OS ANIMAIS?}

As linhas acima destacaram os contemporâneos que julgam que os tratamentos infligidos pelos seres humanos aos animais devem ser substancialmente, ou mesmo radicalmente, modificados. No entanto, seria falso acreditar que todos os filósofos pensam que existem direitos do animal ou que sejam defensores da liberação animal. Existem argumentos sérios contra tais teorias (PELIZZOLI, 2003).

R.G. Frey contesta a tese de Geinberg-Nelson, segundo a qual os direitos são gerados pela posse de interesses. Segundo ele, pode-se interpretar a noção de interesses num sentido objetivo; nesse caso, os interesses dependem de necessidades. E, certamente, há interesses animais. Mas o argumento é muito mais forte: pois é do interesse de uma planta ser regada, do interesse de um motor ser lubrificado, etc. (FREY, 1987).

Seria preciso então conceder interesses, e portanto direitos, às plantas e aos objetos artificiais. A questão não muda, se interpretamos a noção de interesse num sentido subje- 
tivo; nesse caso, os interesses dependem de desejos. Mas " $X$ deseja $Y$ " pode ser analisado deste modo: (1) Y faz falta a X e (2) X pode dizer: "A frase: 'Y me faz falta' é verdadeira". Não se falar de desejos animais na ausência de uma linguagem suficientemente sofisticada da parte deles (que contenha a distinção entre frase e proposição; que evidencie o fato de que a verdade de uma proposição é, ao menos em parte, função de um estado de coisas) (FREY, 1987).

M. P. T. Leahy afirma:

[...] os animais são criaturas primitivas. Eles manifestam de forma pré-linguística amostra de atributos humanos (deliberação, escolha, desejos, medo, cólera, crenças, etc.), o que revela a similaridade de seu comportamento com o dos seres humanos, mas eles, propriamente falando, não transformaram essa herança pré-linguística pela elaboração de uma linguagem. (LEAHY, 1991, p. 342)

Sua forma de vida é, portanto, muito alheia à nossa, para que seja necessário ir além de uma teoria das obrigações indiretas, no que diz respeito a eles (LEAHY, 1991). Carruthers considera que o utilitarismo é reflexivamente instável (isto é, vai contra os traços fundamentais do pensamento moral). Assim, ele prefere uma teoria contratualista da moral, mas os animais não são agentes racionais no sentido pleno do termo; portanto, eles não podem ser parte integrante do contrato, havendo em relação a eles apenas obrigações indiretas (CARRUTHERS, 1992).

\section{UMA GEOGRAFIA HUMANO-ANIMAL?}

Os animais não humanos têm sido um foco permanente e significativo de geógrafos (WOLCH, EMEL, \& WILBERT, 2000). Ao longo da primeira metade do século XX, duas abordagens para o campo de investigação - zoogeografia e cultural - eram claramente articuladas. Zoogeografia, tipicamente afiliada com geografia física, com foco na distribuição geográfica dos animais.

Um ramo identificável como "animal geography" foi ativamente pesquisado, pelo menos desde Newbigin (1913). A ambição era a de estabelecer leis gerais de como os animais se dispersam através da superfície da Terra ou, em escalas menores, para estabelecer padrões de co-variação espacial entre animais e outros fatores ambientais.

A geografia cultural animal surgiu no início dos anos 1960, envolvendo estudos de como os seres humanos influenciam animais, "números e distribuições", ecoando a ênfase zoogeográfica sobre espaço e distribuições espaciais (BENNETT, 1960). Esses estudos articulados com a ecologia cultural, que iniciou com os estudos sobre as origens da domesticação animal, estavam preocupados com distribuições e difusões dos animais e caracterizava por uma atenção ao lugar, região e, acima de tudo, paisagem. O artigo de Sauer (1952) documenta o papel pioneiro da domesticação de animais na conversão de "paisagens naturais" em "paisagens culturais". 


\section{REPENSANDO CULTURA, NATUREZA E SUBJETIVIDADE}

Por uma série de razões, o termo "geografia animal" tinha desaparecido do discurso geográfico no último trimestre do século XX. Na década de 1990, no entanto, com interesse renovado, inspirados pelo encontro entre o ser humano geografia e teoria social, estudos culturais e do ambiente da ética ambiental nos Estados Unidos, Wolch e Emel $(1995,1998)$, tentam "trazer os animais para dentro" ${ }^{1}$. Tuan (1984), que traçou a desigual e "paternalista" relação de poder sobre os animais de companhia, foi talvez o melhor exemplo mais conhecido dessa retomada da geografia animal. Philo e Wilbert (2000) perguntaram o que poderia se desenvolver se os conceitos da "nova" geografia cultural fossem aplicados para as relações humano-animal.

O surgimento de novas pesquisas na teoria social e estudos culturais levou a uma profunda revisão da cultura e, especialmente, um repensar da subjetividade.

Junto com muitos cientistas naturais, geógrafos e vários intelectuais repensaram os conceitos pós-estruturalistas e começaram a discutir a subjetividade dos animais e a necessidade de descompactar a "caixa preta" da natureza para entendimentos contemporâneos do mundo (THRIFT, 2000). Em particular, o foco foi o papel dos animais na construção social da cultura e do indivíduo, da natureza da subjetividade animal, e sua interação como agente. Para os geógrafos, o tópico inclui a divisão humano-animal, especialmente como e por que essa relação muda ao longo do tempo e do espaço e das identidades; as formas em que as representações de animais moldam a identidade pessoal e coletiva (ANDERSON, 1997; ELDER; WOLCH; EMEL, 1998).

Debates sobre a construção social de paisagens e lugares levaram geógrafos animais a explorar como os animais e as redes em que são integrados deixam impressões em determinados lugares, regiões e paisagens, fazendo dos estudos animais fundamentais para entender a dinâmica socioambiental. Esses lugares incluem locais especiais, como jardins zoológicos, limítrofes, onde os seres humanos e não humanos compartilham um espaço livre, sendo ambos agentes de mudanças econômicas ou sociais que os afetam (ANDERSON, 1995; DAVIES, 2000; GRUFFUDD, 2000).

Os geógrafos têm feito uma série de estudos sobre a inclusão e exclusão de certos animais de determinados tipos de lugares, incluindo o urbano (PHILO, 1995; GAYNOR, 1999; GRIFTHS; POULTER; SIBLEY; 2000). Ver animais como sujeitos sugere a criação de uma "Zoopolis", um lugar onde pessoas e animais convivem e podem ajudar/reestabeler redes de cuidados entre eles (WOLCH, 1996).

Argumentos sobre a subjetividade animal levam alguns geógrafos para a ética ambiental e, sobretudo, para um repensar sobre os animais no terreno moral (MATLESS, 1994). Lynn (1998) desenvolveu o conceito de "comunidade geográfica" para abranger questões éticas que envolvem pessoas, animais e natureza. Elder, Wolch e Emel (1998)

1 WOLCH, J.; EMEL J., 1995.. Esse artigo abre uma edição da Environment and Planning D, exclusivamente dedicada à "animal geographies". 
recomendaram uma "pratique sauvage" ou uma democracia radical, que engloba não só as pessoas subalternas, mas animais também.

\section{CONSIDERAÇÕES FINAIS: O FUTURO DA GEOGRAFIA ANIMAL}

A Geografia, como disciplina, tem proporcionado o significativo avanço do constructo histórico-cultural das relações animais humanos e não humanos, bem como seu caráter de raça e gênero e sua inserção econômica. Esses trabalhos devem continuar, afirma Wolch (1996). Existem vastas áreas ainda carentes de análises. A construção histórica e cotidiana das narrativas díspares e representações precisam de mais atenção dos estudiosos, como afirma Lorimer (2005).

A visão de uma nova interpretação da Geografia, uma geografia desumana, em que humanos e não humanos estejam contemplados, em que possamos repensar essa divisão humano-físico (LATOUR, 1988). As associações e relações entre humanos e não humanos devem estar presente nesse híbrido conhecimento e estudo, para que, desviando o foco exclusivamente para o humano ou para o físico, se possa produzir uma geografia humano-animal no sentido de ser ampla e complexa como exige nossa sociedade contemporânea, ou seria uma geografia desumana?

\section{REFERÊNCIAS}

AIKEN, L. Attitudes and related psychosocial constructs: Theories, assessment, and research. Sage, 2002.

ALBARRACIN, D. E; JOHNSON, B.T.; ZANNA, M.P. The handbook of attitudes. Lawrence Erlbaum Associates Publishers, 2005.

ALCOCK, J. E.; CARMENT, D. W.; SADAVA, S. W. A textbook of social psychology. Prentice Hall, 2005.

ANDERSON, K. Culture and nature at the Adelaide Zoo: At the frontiers of "human" geography. In: Transactions of the Institute of British Geographers, n. 20, 1995, p. 275-294.

A walk on the wild side: a critical geography of domestication. In: Progress in Human Geography, n. 21, 1997, p. 463-485,.

ARLUKE, A; SANDERS, C. R. Regarding animals. Philadelphia: Temple University Press, 1996.

ARONSON, E.; WILSON, T. D.; AKERT, R. M. Social psychology. Pearson Higher Ed, 2007.

BARON, R. A. et al. Mastering social psychology. Boston: Pearson, 2007.

BECKER, L. C. The priority of human interests. In REGAN, T; Singer, P. (Eds.) Animal rights and human obligations. New Jersey: Prentice-Hall, 1989. p. 87-94.

BENNETT, C. F. Cultural animal geography: an inviting field of research. Professional Geographer, v. 12, n. 5, 1960, p.12-14.

BENTON, T. Natural relations: ecology, animal rights and social justice. Londres: Verso, 1993.

BOUDIEU, P. A distinção: crítica social do julgamento. Porto Alegre: Zouk, 2011.

CARRUTHERS P. The animal issue: moral theory in practice. Cambridge: Univ. Press, 1992.

CARTMILL, M. View to a death in the morning. Cambridge: Harvard University Press, 1993. 
CASANOVA, C. Introdução à antropologia biológica: princípios evolutivos, genética e primatologia. Lisboa: ISCSP/FCT, 2006.

CHAPOUTHIER, G.; NOUET, J.C.(Ed.). Les droits de l'animal aujourd'hui. Arléa-Corlet, 1997.

CIALDINI, R. B. Influence: science and practice. Boston: Allyn and Bacon, 2001.

CLARK S. R .L. The moral status of animals. Oxford: Clarendon Press, 1977.

COHEN, J. About streaks liking to be eaten: the conflicting views of symbolic interactionistis an talcott, parsons concerning the nature of relations between persons and non-humans objects. In: Symbolic Interactions. v. 12, 1989, p. 191-214.

COSTA, S. G. Sociologia do relacionamento humanos/outros animais: percepções sociais da superioridade humana (análise de uma amostra da freguesia de Almada). Dissertação (Mestrado em Ciências Sociais), Universidade Técnica de Lisboa, Lisboa, 2004.

CULLEN, D. Dog's killing stirs outrage. In: Boston Globe, Boston, 1992, p. 1-24. 9 abr. 1992.

DAVIES, G. Virtual animals in electronic zoos: the changing geographies of animal capture and display. In: PHILO, C.; WILBERT, C. (Eds.). Animal spaces, beastly places: new geographies of human-animal relations. New York: Routledge, 2000. p. 243-246.

DIERAUER, Urs. Tier und Mensch im Denken der Antike: Studien zur Tierpsychologie, Anthropologie und Ethik. BR Gruner Publishing Company, 1977.

DOUGLAS, M. Implict meanings. London: Routledge and Kegan Paul, 1975.

ELDER, G.; WOLCH, J.; EMEL, J. Le pratique sauvage: race, place, and the humananimal divide. In: WOLCH J.; EMEL, J. (Eds.). Animal geographies: place, politics, and identity in the nature-culture borderlands. London: Verso, 1998. p. 72-90.

FEINBERG J. The rights of animals and unborn generations. In: BLACKSTONE, W. T. (Ed.). Philosophy an Environment. Athens: Univ. Of Georgia Press, 1974. p. 43-68.

FIDDES, N. Meat: A natural symbol. Psychology Press, 2004.

FRANKLIN, A. Animal \& modern culture: a sociology of human-animal relations in modernity. London: Sage Publications, 1999.

FREY R. Interests and rights. The case against animals. Oxford: Clarendon Press, 1987.

GAYNOR, A. Regulation, resistance and the residential area: the keeping of productive animals in twentiethcentury Perth, Western Australia. In: Urban Policy and Research, v. 17, 1999, p. 7-16.

GIDDENS, A. Sociologia. Porto Alegre: Artmed, 2005

GIDDENS, A. A constituição da sociedade. 2 ed. SãoPaulo: Editora Martins Fontes, 2003.

GOFFI J. Y. Le Philosophe at ses animaux. Du statut ethique de l'animal. Nimes: Jacqueline Chambon, 1994.

GOODMAN, D.; REDCLIFT, M. Refashioning nature - food, ecology and Nature. London: Routledge, 1991.

GRIFTHS, H.; POULTER, I.; SIBLEY, D. Feral cats in the city. In: PHILO, C.; WILBERT, C. (Eds.). Animal spaces, beastly places: new geographies of human-animal relations. New York: Routledge, 2000. p. 56-70.

GRUFFUDD, P. Biological cultivation: Lubetkin's modernism at London Zoo in the 1930s. In: PHILO, C.; WILBERT, C. (Eds.). Animal spaces, beastly places: new geographies of human-animal relations. New York: Routledge, 2000. p. 222-242.

HARE R. M. Essays on bioethics. Oxford: Clarendon Press, 1993

INGOLD, T. What is animal? London: Routledge, 1994.

JONES, M. Social psychology of prejudice. New Jersey: Prentice Hall, 2002.

LATOUR B. Mixing humans end nonhumans together: the sociology of a door-closer. In: Social Problems, v. 35, 1988, p. 298-310. 
LEAHY M. P. T. Against liberation: Putting animals in perspective. Londres/Nova York: Routledge, 1991. LINZEY A. Christianity and the rigths of animals. Londres: SPCK, 1987.

LORIMER, H. Cultural geography: the busyness of being more-than-representational. Progress in human geography, v. 29, n. 1, p. 83-94, 2005.

LYNN, W. S. Animals, ethics and geography. In: WOLCH, J.; EMEL, J. (Eds.). Animal geographies: place, politics, and identity in the nature-culture borderlands. London: Verso. Animal Geographies, v. 411, 1998, p. 280-297.

MACIEL, M. E. (Org.). Pensar/escrever: o animal. Ensaios de zoopoética e biopolítica. Santa Catarina: UFSC, 2011.

MACNAGHTEN, P.; URRY, J. Towards a sociology of nature. In: Sociology, v. 29, n. 2, 1995, p.124-137.

MACRAE, C. et al. Stereotypes and stereotyping. New York: Guilford Publications, 1996

MAGEL, C. R. Keyguide to information sources on animal rights. Jefferson: McFarland, 1989.

MATLESS, D. Moral geography in Broadland. Ecumene, v. 1, 1994, p. 127-156.

MCGARTY, C. Categorization in Social Psychology. London: Sage Publications, 1999.

MENNELL, S. All manners of food. Oxford: Blackwell, 1993.

MIDGLEY. M. Animals and why they matter. Athens: The University of Georgia Press, 1983.

MURPHY, R. Sociology as if nature did not matter: an ecological critique. In: British Journal of Sociology, v. 46, n. 4,1995 , p. $688-707$.

NELSON, J. L. Animals, handicapped children and the tragedy of marginal cases. In: Journal of medical ethics, v. 14, 2006, p.191-193.

NEWBIGIN, M. I. Animal geography: the faunas of the natural regions of the globe. Oxford: Clarendon. 1913.

NIBERT, David. Animal rights/human rights: entanglements of oppression and liberation. Lanham: Rowman \& Littlefield Publishers, 2002.

PASSMORE, J. Man's responsibility for nature. 2. Ed. Londres: Duckworth, 1980.

PELIZZOLI, M. L. Correntes da ética ambiental. Petrópolis: Vozes, 2003.

PHILO, C. Animals, geography and the city: notes on inclusions and exclusions. In: Environment and planning D: society and space, v. 13, 1995, p. 655-681.

.; WILBERT, C. (Eds.). Animal spaces, beastly places: new geographies of human-animal relations. New York: Routledge, 2000.

REGAN, T. The case of animals rights. Londres: Routledge \& Kegan Paul, 2006.

RITVO, H. The animal estate: the English and other creatures in the Victorian age. Cambridge: Harvard Press University, 1987.

ROLLIN, B. E. Animal rights and human morality. New York: Prometheus Books, 2006.

SAPONTZIS S. F. Morals, reason, and aminals. Filadelfia: Temple University Press, 1987.

SAUER, C. O. Agricultural origins and dispersals. New York: American Geographical Society, 1952.

SERPELL, J.; PAUL, E. Pets and positive attitudes to animals. In: MANNING, A; SERPELL, J. (Eds). Animals and Human Society. London: Routledge, 2006.

(Ed.). The domestic dog: Its evolution behaviour and interactions with people. Cambridge: Cambridge University Press, 1995.

In the company of animals. A study of human-animal relationship. Cambridge: Cambridge

University Press. 1996. 
SINGER P. Libertação animal. Porto Alegre; Lugano, 2004.

. All animals are equal. In: REGAN, T.; SINGER, P. (Eds.) Animal Rights and Humans Obligations. New Jersey: Prentice-Hall, 1989.

SMITH, E.R.; MACKIE, D.M. Social psychology . Psychology Press/Taylor \& Francis (UK), 2007.

SORABJI, R. Animal minds \& human morals: the origins of the western debate. New York: Cornell University Press, 1995.

TESTER, K. Animals and society: the humanity of animals rights. London: Routledge, 1992.

THOMAS, K. O homem e o mundo natural. São Paulo: Companhia das Letras, 1983

THRIFT, N. The future of geography. Geoforum, v. 33, n. 3, p. 291-298, 2002.

TUAN, Yi-Fu. Dominance \& affection: The making of pets. New Haven, CT: Yale University Press, 1984.

TURKE, S. The Second Self. New York: Simon \& Schuster, 1984.

TWIGG, J. Vegetarianism and the meaning of meat. In: MORCOTT, A. (Ed.) The sociology of food and eating. London: Gower, 1983.

VIALLES, N. Animal to edible. Cambridge: Cambridge University Press, 1994.

WILBERT, C. Anti-this-against-that: resistances along a human non-human axis. In: SHARP, J. et al. (Eds.). Entanglements of power. London: Routledge, 2000, p. 238-255.

WOLCH J. Zoöpolis. Capitalism nature socialism, v. 7, 1996, p. 21-48.

.; EMEL, J. (Eds.). Theme issue on bringing the animals back in. In: Environment and Planning D: Society and Space, v. 13, 1995, p. 631-760.

.; EMEL, J.; WILBERT, C. Reanimating cultural geography. In: ANDERSON, K.; DOMOSH M.; THRIFT, N.; PILE, S. (Eds.). Handbook of cultural geography. London: Sage, 2000.

.; WEST, K.; GAINES, T. E. Transspecies urban theory. In: Environment and Planning D. Society and Space, v. 13, 1995, p. 735-760.

YZERBYT, V.; LEYENS, Jean-P. Psicologia Social. Lisboa: Edições 70: 2004.

Recebido em 09/10/2012

Aceito para publicação em 22/10/2013 